\title{
Hyperleukocytosis in a child with Leukemia-Importance of critical management in a developing country
}

\author{
Stepheson J. ${ }^{1}$, Reddy ${ }^{2}$, Soundara Pandian L.P. ${ }^{3}$, Nisha K. ${ }^{4}$, Scott J.J. ${ }^{5}$ \\ ${ }^{1}$ Dr. Jessintha Stephenson, ${ }^{2}$ Dr. Yuvaram Reddy (Fellow), ${ }^{3}$ Dr. Soundara Pandian Lakshmi Priya, ${ }^{4}$ Dr. Nisha. K Post \\ Graduate, final year, Sri Ramachandra University, ${ }^{5}$ Prof. J. Julius Scott, Professor, all authors are affiliated with \\ Department of Pediatrics, Division of Pediatric Hemato-Oncology, Department of Pathology, Sri Ramachandra \\ University, Porur, Chennai, Tamilnadu, India
}

Address for Correspondence: Dr. Julius Scott, Professor of Pediatrics, Division of PediatricHemato Oncology, Sri Ramachandra Medical Centre, No.1, Ramachandra Nagar, Porur, Chennai. Email: jxscott@hotmail.com

\begin{abstract}
Leukostasis is a pathological condition in which excessive amounts cause coalescence and sludgin leading to thrombosis, hemorrhage, respiratory distress, and renal failure. It is imperative that it is treated urgently and efficiently.We report an eleven year old boy presented to our emergency room with low-grade fever for 3 days. Clinical examination showed pallor and hepatosplenomegaly, and blood test showed low hemoglobin, low platelet count, and increased WBC count of $8,86,960$ cells $/ \mathrm{mm}^{3}$, which were primarily lymphoblasts. Additionally, patient had dyselectrolytemia with hyperkalemia, hypocalcaemia, hyperphosphatemia, and hyperuricemia. He was treated with hydration, Alkalinization, Allopurinol, exchange transfusions, and Rasburicase. Flow cytometry confirmed the diagnosis of acute T-cell lymphoblastic leukemia. This case emphasizes the importance of swift and effective use of exchange transfusion in the management of hyperleukocytosis as it is more readily available and illustrates that it is almost, if not equally, effective as Leukoapheresis.
\end{abstract}

Key words: Leukostasis, Hyperleukocytosis, Leukemia, Children

\section{Introduction}

As hyperleukocytosis cause increased risk of leukostasis and sequel such as intracranial hemorrhage, respiratory failure and thrombosis, it requires urgent cytoreduction [1,2]. Although Leukoapheresis is the procedure of choice, it may not be affordable in primary health care centre. This case report demonstrates that stabilization in such situations can be obtained with exchange transfusions with a similar degree of efficacy to Leukoapheresis.

\section{Case Report}

An 11year old boy presented to the emergency room with a history of low-grade fever for 3 days. On clinical examination, he appeared dull, listless and afebrile. Vitals were stable with a pulse rate of $82 / \mathrm{min}$, blood pressure of $110 / 70 \mathrm{mmHg}$ and respiratory rate of $20 / \mathrm{min}$. He appeared pale, his liver was palpable $2 \mathrm{~cm}$ below the right costal margin, and spleen was enlarged to $7 \mathrm{~cm}$ below the left costal margin and other systemic examination was normal. Laboratory investigations revealed a total within normal limits. Serum electrolytes results were sodium - $143 \mathrm{mmol} / \mathrm{L}$, potassium$12.9 \mathrm{mmol} / \mathrm{L}$, bicarbonate $-22 \mathrm{mmol} / \mathrm{L}$, calcium $-4 \mathrm{mg} / \mathrm{dL}$, phosphorus $-12.0 \mathrm{mg} / \mathrm{dL}$, uric acid $-19.5 \mathrm{mg} / \mathrm{dL}$ and $\mathrm{LDH}-$ $4530 \mathrm{U} / \mathrm{L}$. Flow cytometry confirmed the diagnosis of acute T-cell lymphoblastic leukemia. Chest X-ray showed no cardiomegaly or mediastinal mass, CSF cytology was normal. Blood Leukemia cytogenetic profile was normal. Fluorescent in-situ hybridization for BCR/ABL was negative. The close monitoring of white blood cells done and summarized in Table 1. The patient was urgently hydrated with Alkalinization, and was started on Allopurinol and underwent two sessions of exchange transfusion with fresh frozen plasma. In view of his high risk for tumor lysis/renal

Manuscript received: $30^{\text {th }}$ November 2016

Reviewed: $08^{\text {th }}$ December 2016

Author Corrected: $18^{\text {th }}$ December 2016

Accepted for Publication: 27 $7^{\text {th }}$ December 2016 
failure, he was also given one dose of Rasburicase. Following therapy within 24 hours, his electrolyte profile normalized. He was started on hydroxyurea on day 2 along with Prednisolone after confirmation of the diagnosis. The patient was continued with chemotherapy regimen of Vincristine, Daunorubicin and L-Asparaginase subsequently.

Table-1: Decreasing trend of white blood cells periodically

\begin{tabular}{|c|c|c|c|c|c|c|c|c|c|c|c|}
\hline 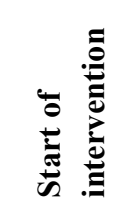 & 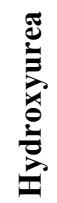 & 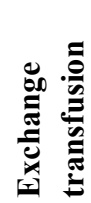 & $\frac{0}{\frac{0}{0}}$ & & & & 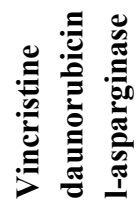 & & & & \\
\hline Days & 1 & 2 & 3 & 4 & 5 & 6 & 7 & 8 & 9 & 10 & 11 \\
\hline ن & $\begin{array}{l}8 \\
8 \\
0 \\
\infty \\
\infty\end{array}$ & $\begin{array}{l}2 \\
2 \\
\infty \\
\infty \\
0\end{array}$ & 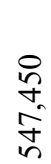 & $\begin{array}{l}8 \\
\text { ते } \\
0 \\
\text { ஸे }\end{array}$ & 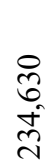 & 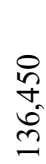 & $\frac{8}{6}$ & $\frac{\stackrel{8}{\Omega}}{\stackrel{0}{\circ}}$ & 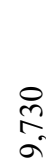 & $\underset{\text { m }}{\stackrel{8}{8}}$ & ஜn \\
\hline
\end{tabular}

One week after the initial presentation, repeat investigations showed uric acid $1.5 \mathrm{mg} / \mathrm{dL}$, sodium - $139 \mathrm{mmol} / \mathrm{L}$, potassium- $4.9 \mathrm{mmol} / \mathrm{L}$, hemoglobin $-12.2 \mathrm{~g} / \mathrm{dL}$, total white blood cell count $-20,190$ cells $/ \mathrm{mm}^{3}$ with $92 \%$ lymphoblasts, $4 \%$ neutrophils, $2 \%$ myelocytes and $2 \%$ eosinophils. On discharge, the patient's total WBC count was $2,300 \mathrm{cells}^{\mathrm{s}} / \mathrm{mm}^{3}$. Now 1month after chemotherapy, his WBC count normalized to 3,330 cells/ $\mathrm{mm}^{3}$.the patient is in the remission phase and undergoing chemotherapy.

\section{Discussion}

Leucocytosis can be defined as an elevated WBC count and is a commonly occurring phenomenon in infections. Hyperleukocytosis, is any leukocyte count above the set count of 50,000 cells $/ \mathrm{mm}^{3}[1,2]$. It is prudent to note, however, that hyperleukocytosis, regardless of etiology, due to leukostasis. Leukostasis is a pathological condition in which excessive amounts of leukocytes in the blood stream along with abnormal endothelial adhesion molecules cause coalescence and sludging of white blood cells further leading to thrombosis, hemorrhage, respiratory distress, and renal failure. Additional complications such as hyperphosphatemia, hypocalcaemia, hyperkalemia can be caused by tumor lysis syndrome due to treatment of hyperleukocytosis or spontaneously $[3,4]$.

Different leukemia types carry various incidences of hyperleukocytosis and leukostasis and the statistics are difficult to define clearly in general population. A general pattern of pathology and presentation may be observed; however, while hyperleukocytosis occurs in around $10-20 \%$ of patients with acute myelogenous leukemia (AML), it occurs more often in acute lymphoblastic leukemia. Furthermore, the incidence of leukostasis increases when the cell count is above 0.1 million cells/ $\mathrm{mm}^{3}$ in AML while in ALL, leukostasis develops much less often $[5,6]$.
Benign elevation in leukocyte count is usually Leukemoid in nature and of myeloid origin and both benign and malignant pathologies can be almost equally considered. Conversely, malignancy is almost the rule in lymphoid hyperleukocytosis. Leukemoid reactions can be suspected when features such as a normal to high Leukocyte Alkaline Phosphatase count (LAP), an increased left shift of neutrophils, polyclonal origin and the absence of malignant blast cells and Auer rods are seen with due clinical correlation [7]. On the other hand, activated neutrophils (e.g., toxic granulation, Dohle bodies, and cytoplasmic vacuoles) point more to reactive neutrophilia which develops in those with bacterial infections or patients treated with growth factors. Confirmation of a diagnosis of malignancy is carried out with flow cytometry, molecular studies, and a bone marrow examination. Cytoreduction and supportive measures are the mainstays of treatment. Cytoreduction can be achieved by Leukoapheresis, a selective removal of leukocytes. The WBC count can be reduced by $30-60 \%$ in a single $1-1.5$ blood volume Leukoapheresis. In most centers in our developing country, however, this technology is not readily available and exchange transfusion offers a reasonable, pragmatic alternative in such situations [8]. Our patient hence underwent 2 episodes of exchange transfusion on the night of admission. He was also given hydroxyurea along with steroids to aid in cytoreduction. 
Hydroxyurea could be used before starting specific treatment for a confirmed diagnosis $[9,10]$.

While cytoreduction helps prevent permanent squeal, it must be accompanied by primary definitive therapy to show significant mortality benefit. Urgent induction of chemotherapy and steroids is mandatory. Tumor lysis syndrome and the resulting dyselectrolytemia should also be adequately managed in an immediate manner.

\section{Conclusion}

Exchange transfusion can be used almost as effectively as Leukoapheresis in rural and resource-poor settings and should be used liberally when needed. While cytoreduction is important, it is mandatory to initiate primary therapy with chemotherapeutic agents and supportive treatment for tumor lysis syndrome and dyselectrolytemia simultaneously.

Funding: Nil, Conflict of interest: None initiated, Permission from IRB: Yes

\section{Reference}

1. Jain R, Bansal D, Marwaha RK. Hyperleukocytosis: emergency management. Indian J Pediatr. 2013 Feb;80(2):144-8. doi: 10.1007/s12098-012-0917-3. Epub 2012 Nov 24.

2. Hilts SV, Shaw CC. Leukemoid blood reactions. N Engl J Med. 1953 Sep 10; 249(11):434-8.

3. Hug V, Keating M, McCredie K, et al. Clinical course and response to treatment of patients with acute myelogenous leukemia presenting with a high leukocyte count. Cancer 1983;52:773-779

4. Aqui N, O'Doherty U. Leukocytapheresis for the treatment of hyperleukocytosis secondary to acute leukemia. Hematology Am Soc Hematol Educ Program.
2014 Dec 5;2014(1):457-60. doi: 10.1182/asheducation2014.1.457. Epub 2014 Nov 18.

5. Gong J, Wu B, Guo T, Zhou S, He B, Peng X. Hyperleukocytosis: A report of five cases and review of the literature. Oncol Lett. 2014 Oct;8(4):1825-1827. Epub 2014 Jul 8.

6. Kong SG, Seo JH, Jun SE, Lee BK, Lim YT. Childhood acute lymphoblasticleukemia with hyperleukocytosis at presentation. Blood Res. 2014 Mar;49(1):29-35. doi: 10.5045/br.2014.49.1.29. Epub 2014 Mar 24.

7. Sung L, Aplenc R, Alonzo TA, Gerbing RB, Gamis AS;Predictors and short-term outcomes of hyperleukocytosis in children with acute myeloid leukemia: a report from the Children's Oncology Group. Haematologica. 2012 Nov;97(11):1770-3. doi: 10.3324/haematol.2012.065490. Epub 2012 Jul 16.

8. Nguyen R, Jeha S, Zhou Y, Cao X, Cheng C, Bhojwani D, et al.The Role of Leukapheresis in the Current Management of Hyperleukocytosis in Newly Diagnosed Childhood Acute Lymphoblastic Leukemia. Pediatr Blood Cancer. 2016 Sep;63(9):1546-51.

9. Badawy SM. The Use of Hydroxyurea and Leukapheresis in Childhood Acute Leukemia With Hyperleukocytosis. J Pediatr Hematol Oncol. 2016 Jul;38(5):407. doi: 10.1097/MPH.0000000000000578.

10. Mamez AC, Raffoux E, Chevret S, Lemiale V, Boissel N, Canet E, Schlemmer B, Dombret H, Azoulay E, Lengliné E. Pre-treatment with oral hydroxyurea prior to intensive chemotherapy improves early survival of patients with high hyperleukocytosis in acute myeloid leukemia. Leuk Lymphoma. 2016 Oct;57(10):2281-8. doi: 10.3109/10428194.2016.1142083. Epub 2016 Feb 5.

\section{How to cite this article?}

Stepheson J., Reddy Y, Soundara Pandian L.P., Nisha K., Scott J.J. Hyperleukocytosis in a child with LeukemiaImportance of critical management in a developing country. J PediatrRes.2016;3(12):893895.doi:10.17511/ijpr.2016.i12.07. 